\title{
SERIOUS DIAPHYSIS FRACTURE INDUCTED BY PERSISTENT USE OF NASAL CORTICOID: CASE REPORT
}

Karla Valéria Miranda de Campos (Faculdade de Enfermagem e Medicina Nova Esperança, João Pessoa, PB, Brasil), Déborah Thaise Bezerra de Campos (Faculdade de Enfermagem e Medicina Nova Esperança, João Pessoa, PB, Brasil), André Chaves de Miranda Campos (Faculdade de Enfermagem e Medicina Nova

Esperança, João Pessoa, PB, Brasil), Teresa Patricia Acebey Crespo (Faculdade de Enfermagem e Medicina Nova Esperança, João Pessoa, PB, Brasil), Alessandra de Sousa Braz (Universidade Federal da Paraíba, João Pessoa, PB, Brasil), Alexandre Schuler Barros (Faculdade de Enfermagem e Medicina Nova Esperança, João Pessoa, PB, Brasil)

\section{BACKGROUND}

: Osteoporosis is an osteometabolic disease that its main characteristic is the loss of strength or bone resistance, increasing the risk of lower impact fractures. The bone damage is accentuated in areas of trabecular bone predominance, however, occur minor losses in long bones diaphysis, that mainly consist in cortical bone. It may be associated with age, bad social and nutritional habits, drugs and genetic factors. Continuous use of corticoid, in his diversify presentations, may speed up the process, because it reduces the osteoblast production and stimulates osteoclastogenesis, the apoptosis of osteocytes, raise the intestinal excretion of calcium and inhibits the renal tubular absorption.

\section{CASE REPORT}

37 years old, men, public employee, affirmed pain in the medial region of the right thigh during play soccer at January, in 2019, with serious fracture at the medium third of the right femur. Have been using nasal corticoid, budesonide $50 \mathrm{mcg} /$ dose, for 5 years to treat allergic rhinitis, with an initial dose of 1 puff/day for a month and, posteriorly, by his need, in general twice a week. He denial alcoholism and smoking. He made the bone densitometry exam with Z-score in lumbar region, resulting in -2,3. Laboratorial exams for bone metabolism, electrophoresis and testosterone were normal. Due to the fracture picture, he had surgery and a metallic stem was insert for bone fixation, presenting a good evolution.

\section{CONCLUSION}

The use of oral glucocorticoid (GC) is one of the main causes of secondary osteoporosis. That association is rare when the presentation of GC is nasal and occur in compact bones. The case in discussion have these characteristics, with the serious fracture by a low impact at femur diaphysis, even in short doses of the medication. 